\title{
Two years study of prevalence and antibiotic resistance pattern of Gram-negative bacteria isolated from surgical site infections in the North of Iran
}

\author{
Hossein Hemmati ${ }^{1}$, Meysam Hasannejad-Bibalan² ${ }^{2}$ Sara Khoshdoz ${ }^{1}$, Parisa Khoshdoz ${ }^{1}$, \\ Tofigh Yaghubi Kalurazi ${ }^{*}\left[\mathbb{D}\right.$, Hadi Sedigh Ebrahim-Saraie ${ }^{1^{*}} \mathbb{C}$ and Soheila Nalban ${ }^{1}$
}

\begin{abstract}
Objective: The present study aimed to investigate the frequency and antibiotic susceptibility pattern of Gram-negative bacteria (GNB) isolated from surgical site infections (SSIs) in the North of Iran.

Results: This cross-sectional study conducted over a two-year period during 2018-2020 on all cases of SSIs who had a positive culture for a GNB. Standard microbiological tests were followed for the bacterial isolation and identification. Antimicrobial susceptibility profiles were determined using disk diffusion method. During the study period, a total of 78 nonduplicated GNB isolated from SSIs. The most prevalent surgical procedures were fracture fixation (37.2\%), and tissue debridement (23.1\%). Klebsiella isolates showed the highest isolation rate (29.5\%) followed by Enterobacter (28.2\%), and Acinetobacter (16.7\%). Antibiotic susceptibility results showed that Acinetobacter isolates were almost resistant to all of the tested antibiotics, except gentamicin, co-trimoxazole, and meropenem. Enterobacteriaceae isolates showed the lowest resistance against amikacin, co-trimoxazole, and imipenem. Overall, 49 (62.8\%) of isolates were multiple drug-resistant (MDR). In summary, a remarkable rate of MDR isolates which showed an increasing trend during recent years is a serious alarm for the management of SSIs caused by GNB. Moreover, the results of regional assessments, provide good epidemiological background for comparing our situation with other regions.
\end{abstract}

Keywords: Surgical site infection, Gram-negative bacteria, Antibiotic resistance, MDR

\section{Introduction}

Surgical site infections (SSIs) are a devastating complication of hospitalization and one of the global health problems [1]. These infections may involve only the skin and subcutaneous tissues or deep infections involving organs or body spaces [2]. SSIs remain a major cause of morbidity and mortality, impose a high cost on the healthcare

\footnotetext{
*Correspondence: tofigh.yaghubik@gmail.com; seddigh.hadi@gmail.com; seddigh.hadi@gums.ac.ir

${ }^{1}$ Razi Clinical Research Development Unit, Razi Hospital, Guilan University of Medical Sciences, Rasht, Iran

Full list of author information is available at the end of the article
}

system. SSI is the leading health-care-associated infection in the developing countries which also has a markedly higher incidence compared to developed countries $[3,4]$. Approximately, the SSI incidence is 5.6 per 100 surgical procedures in developing countries, while in the USA and different European countries the incidence was 2.6 and 2.9 per 100 surgical procedures, respectively [5-7].

The majority of SSIs caused by opportunistic pathogens that originate from the patient's endogenous microflora. Staphylococci, enterococci, Pseudomonas aeruginosa, Acinetobacter baumannii, Enterobacteriaceae, and Candida albicans are the most frequently isolated pathogens 
in SSIs [5]. However, the epidemiological studies indicate the heterogeneous nature of these infections and the incidence varies widely between procedures, wound classes, and regions [8].

Recently, the emergence of multiple drug-resistant (MDR) strains of hospital pathogens become a global challenge for clinicians $[9,10]$. Consequently, the increase of hospital stays, readmissions, additional use of antimicrobials, and treatment failure was expected for patients infected by MDR strains [11]. The rapid rise of MDR Gram-negative bacteria (GNB) is of particular concern since higher mortality risk of nosocomial infections caused by MDR vs. non-MDR GNBs was noted $[12,13]$.

Given pathogen-specific differences and the many variables associated with adverse outcomes of SSIs, surveillance data about trends in etiology and antimicrobial resistance is a rational way to overcome the risk of drug resistance and treatment failure. Therefore, the present study aimed to determine the prevalence and antibiotic resistance pattern of GNB isolated from SSIs in North Iran. This information can help clinicians to choose effective empirical therapies and provide good epidemiological profiles to compare our situation with others.

\section{Main text \\ Methods \\ Study design and subjects}

This retrospective cross-sectional study was conducted on patients with SSIs for two years from March 2018 to March 2020 in a central medical and educational hospital in north Iran. According to Centers for Disease Control and Prevention (CDC) recommendation, SSI was defined as infection occurs within 30 days after the operative procedure and involves only skin and subcutaneous tissue of the incision and organisms isolated from an aseptically obtained culture of fluid or tissue from the superficial incision [14]. During the study, demographic and clinical information of patients who had an SSI caused by GNB were included. The included clinical information consists of surgical procedures, underlying diseases, hospitalization time, hospitalized ward and outcome of patients'. This study was approved by the Ethics Committee of the Guilan University of Medical Sciences and was in accordance with the declaration of Helsinki. However, the committee waived the need for informed consent, because we only used medical records. Also, all personal details of patients were kept strictly confidential.

\section{Microbiological procedures}

Using aseptic conditions samples either swabs or aspiration were obtained from patients and immediately transferred to the microbiology laboratory. Standard microbiological methods were used for the isolation and identification of the GNB. Briefly, wound samples inoculated to blood, and MacConkey agars and incubated aerobically at $37{ }^{\circ} \mathrm{C}$ for $24-48 \mathrm{~h}$. Then, all GNB were identified based on routine microbiological procedures including reaction in Triple Sugar Iron agar, Simmons' citrate agar, Christensen's urea agar, Indole test, Methyl red and Voges-Proskauer tests [15]. Antimicrobial susceptibility testing against locally available antibiotics was carried out by the disk diffusion method on Mueller-Hinton agar (Merck, Germany) according to the recommendations of the Clinical and Laboratory Standards Institute (CLSI) [16]. The selection of antimicrobial disks (MAST, UK) and interpretation of results for each pathogen was based on CLSI recommendation. Escherichia coli ATCC 25922 and Pseudomonas aeruginosa ATCC 27853 strains were used for quality control purposes. MDR defined as non-susceptible to $\geq 1$ agent in $\geq 3$ antimicrobial categories [17].

\section{Statically analysis}

The analysis was performed by using SPSS $^{\mathrm{TM}}$ software, version 21.0 (IBM Corp., USA). The results are presented as descriptive statistics in terms of relative frequency. Values were expressed as the mean \pm standard deviation (continuous variables) or percentages of the group (categorical variables). Chi-square or Fisher's exact tests were used to determine the significance of differences. P-value less than 0.05 was considered as a cut off point for statistically significant.

\section{Results}

During the study period, a total of 3781 surgical producers were performed in studied hospital, of which 78 (2.1\%) nonduplicated GNB isolated from SSIs. Out of the 78 culture-positive cases, 24 (30.8\%) belonged to females and $54(69.2 \%)$ to male cases. The mean age of the patients was $49.0 \pm 19.6($ Mean $\pm S D)$ years with an age range from 10 to 85 years. The majority of patients were hospitalized in the orthopedic ward (37.2\%) followed by neurosurgery intensive care unit (ICU) (26.9\%), and general ICU (11.5\%). The most prevalent surgical procedures were fracture fixation (37.2\%), and tissue debridement (23.1\%). The full clinical characteristics of the studied subjects presented in Table 1. Diabetes and hypertension were the most common underlying diseases among studied patients (Additional file 1). Among the 78 cases, the outcome of $7.7 \%$ of patients was death, while $92.3 \%$ of patients were survived. The overall hospitalization time and hospital stay after an SSI among the studied patients were $16.6 \pm 14.6$ days, and $13.8 \pm 12.2$ days, respectively.

Regard to bacterial etiology of SSIs, Klebsiella isolates showed the highest isolation rate $(29.5 \%)$ followed by Enterobacter (28.2\%), and Acinetobacter (16.7\%) 
Table 1 Clinical characteristics of studied cases

\begin{tabular}{|c|c|c|c|}
\hline Variable & Outcome & Frequency & Percent \\
\hline \multirow[t]{2}{*}{ Gender } & Male & 54 & 69.2 \\
\hline & Female & 24 & 30.8 \\
\hline \multirow[t]{7}{*}{ Ward } & Orthopaedic & 29 & 37.2 \\
\hline & Neurosurgery ICU & 21 & 26.9 \\
\hline & General ICU & 9 & 11.5 \\
\hline & General surgery & 7 & 9.0 \\
\hline & $\mathrm{NICU}$ & 6 & 7.7 \\
\hline & Neurology unit & 3 & 3.8 \\
\hline & $\mathrm{PICU}$ & 3 & 3.8 \\
\hline \multirow[t]{12}{*}{ Surgical procedure } & Fracture fixation & 29 & 37.2 \\
\hline & Tissue debridement & 18 & 23.1 \\
\hline & Craniotomy & 10 & 12.8 \\
\hline & Amputation & 7 & 9.0 \\
\hline & Laceration repair & 4 & 5.1 \\
\hline & Laminectomy & 3 & 3.8 \\
\hline & Cranioectomy & 2 & 2.6 \\
\hline & Abdominoplasty & 1 & 1.3 \\
\hline & Cystostomy & 1 & 1.3 \\
\hline & Cranioplasty & 1 & 1.3 \\
\hline & Gastric perforation & 1 & 1.3 \\
\hline & Lumbosacral surgery & 1 & 1.3 \\
\hline \multirow[t]{2}{*}{ Age (year) } & Mean $\pm S D$ & $49.0 \pm 19.6$ & \\
\hline & Range & $10-85$ & \\
\hline Overall hospital stay (day) & Mean $\pm S D$ & $16.6 \pm 14.6$ & \\
\hline $\begin{array}{l}\text { Hospital stay after SSI } \\
\text { (day) }\end{array}$ & Mean $\pm S D$ & $13.8 \pm 12.2$ & \\
\hline
\end{tabular}

ICU intensive care unit, NICU Neonatal intensive care unit, PICU pediatric intensive care unit, SS/ surgical site infection

Table 2 Prevalence of Gram-negative bacteria isolated from SSIs

\begin{tabular}{lcc}
\hline Bacteria & Frequency & Percent \\
\hline Klebsiella spp. & 23 & 29.5 \\
Enterobacter spp. & 22 & 28.2 \\
Acinetobacter spp. & 13 & 16.7 \\
Escherichia coli & 9 & 11.5 \\
Proteus spp. & 5 & 6.4 \\
Pseudomonas spp. & 4 & 5.1 \\
Citrobacter spp. & 2 & 2.6 \\
Total & 78 & 100.0 \\
Enterobacteriaceae & 61 & 78.2 \\
NFGNB & 17 & 21.8 \\
\hline
\end{tabular}

NFGNB non-fermenting Gram-negative bacilli

(Table 2). Antibiotic susceptibility results showed that Acinetobacter isolates were almost resistant to all of the tested antibiotics, except gentamicin, co-trimoxazole, and meropenem. Enterobacteriaceae isolates as the predominant etiology of SSIs showed the lowest resistance against amikacin, co-trimoxazole, and imipenem. Table 3 shows the resistance patterns of isolated pathogens. In overall, 49 (62.8\%) of isolates were MDR (53.5\% in $2018-2019,74.3 \%$ in $2019-2020$ ). The mortality rate among MDR and non-MDR isolates were 10.2, and 3.4\% $(\mathrm{P}=0.28)$, respectively.

\section{Discussion}

Despite the advances in the management of patients undergoing surgery, SSIs remain a significant risk of surgery [18]. The proper treatment of SSIs relies on early identification of infecting etiology and antibiotic susceptibility patterns. However, because of the potentially lifethreatening nature of SSIs, immediate treatment can be precious to save the life of the patients $[19,20]$. So that knowing the local epidemiology and antibiotic resistance pattern will help to reduce the risks of treatment failure.

In our study, Enterobacteriaceae (78.2\%) followed by Acinetobacter spp. (16.7\%) were the most common isolated GNB from SSIs. Despite the variations based on wound class, surgical procedures studied population, or geographical distribution [21], there are several comparable reports showed that Enterobacteriaceae and nonfermenting Gram-negative bacilli (NFGNB) including Acinetobacter spp. and Pseudomonas spp. are the most prevalent GNB in SSIs [22-27]. However, the hospitalized ward can be a key determining factor for changing the isolation pattern of these bacteria. For instance, in our study, NFGNB mostly isolated from patients in ICUs, while Enterobacteriaceae were mostly seen in general wards (Additional file 2). Previously, it has been shown that NFGNB is the main nosocomial pathogen of ICUs [28].

Antibiotic resistance patterns are usually greatly varied, mostly because of differences in the geographical area, type of organisms, and methods used. However, closest to our findings, individual reports from India, Ethiopia, and Rwanda introduced aminoglycosides and carbapenems as the most effective antibiotics against GNB recovered from patients with SSIs [22, 24, 25]. In recent years, the emergence of MDR strains, particularly extendedspectrum beta-lactamases (ESBL) and carbapenemases producing GNB become a growing global problem [2932]. In our results, the estimated rate of MDR isolates was remarkable (62.8\%). Previously, it has been shown that MDR isolates can be associated with different types of SSIs and an increased risk of treatment failure [33, 34].

In summary, a remarkable rate of MDR isolates which showed an increasing trend during recent years is a serious alarm for the management of SSIs caused by GNB. Meanwhile, despite the comparatively stable pattern of causative agents of SSIs at a global scale, the continuous 
Table 3 Antibiotic resistance pattern of Gram-negative bacteria isolated from SSIs ${ }^{\mathrm{a}}$

\begin{tabular}{|c|c|c|c|c|}
\hline Class & Antibiotic & Enterobacteriaceae (\%) & Pseudomonas spp. (\%) & $\begin{array}{l}\text { Acinetobacter } \\
\text { spp. (\%) }\end{array}$ \\
\hline \multirow[t]{2}{*}{ Aminoglycosides } & Amikacin & 25 & 66.7 & 100 \\
\hline & Gentamicin & 64.5 & 100 & 66.7 \\
\hline \multirow[t]{2}{*}{ Carbapenems } & Imipenem & 46.2 & 100 & 100 \\
\hline & Meropenem & 65.5 & 100 & 85.7 \\
\hline Penicillins & Piperacillin & 66.7 & 33.3 & 100 \\
\hline \multirow[t]{5}{*}{ Cephems } & Ceftazidime & 60 & 50 & 100 \\
\hline & Cefepime & 80 & 0 & 100 \\
\hline & Cefixime & 80 & NT & 100 \\
\hline & Ceftriaxone & 56.3 & NT & 100 \\
\hline & Cefoxitin & 55.0 & NT & 100 \\
\hline Fluoroquinolones & Ciprofloxacin & 70.6 & 50 & 100 \\
\hline Macrolides & Azithromycin & 65 & NT & NT \\
\hline Sulfonamides & SXT & 25 & NT & 60 \\
\hline Susceptible strains ${ }^{b}$ & & 3.3 & 0 & 0 \\
\hline MDR & & 67.2 & 50 & 46.2 \\
\hline
\end{tabular}

NT not tested, SXT trimethoprim/sulfamethoxazole, MDR multiple drug-resistant

a The results presented as percentage of resistant strains for each of the tested antibiotics

b The percentage of strains which were susceptible to all of the tested antibiotics

evolution of pathogens in hospital environments necessitates continuous updating on antimicrobial resistance profiles to overcome the risk of treatment failure. Also, more clinical and research attention to patients with diabetes and hypertension who may be at higher risk of infections is recommended.

\section{Limitations}

Our study had several limitations that must be acknowledged. In the present study, we did not explore the microbial spectrum of Gram-positive bacteria as one of the main causes of SSIs. Also, as a limitation of descriptive studies and the unavailability of some information, we were unable to explore the risk of prophylaxis and the emergence of drug-resistant isolates and the risk of postdischarge infections.

\section{Supplementary information}

Supplementary information accompanies this paper at https://doi. org/10.1186/s13104-020-05223-x.

Additional file 1. Distribution of underlying diseases among studied cases.

Additional file 2. Distribution of Gram-negative bacteria based on isolation ward.

\section{Abbreviations}

SSIs: Surgical site infections; MDR: Multiple drug-resistant; GNB: Gramnegative bacteria; CDC: Centers for Disease Control and Prevention; CLSI: Clinical and Laboratory Standards Institute; ICU: Intensive care unit;
NFGNB: Non-fermenting Gram-negative bacilli; ESBL: Extended-spectrum beta-lactamases.

\section{Acknowledgments}

The authors wish to thanks Razi Clinical Research Development Unit of Guilan University of Medical Sciences for their technical supports.

\section{Authors' contributions}

$\mathrm{HH}, \mathrm{MH}, \mathrm{TY}$ and $\mathrm{HS}$ : conceived the study. $\mathrm{HH}, \mathrm{MH}, \mathrm{SKH}, \mathrm{TY}$, and HS: participated in the design of the study and performed the statistical analysis. MH, SKH, PKH $\mathrm{HS}$ and SN: collection and interpreted the data. PKH, MH, TY, and HS: obtained ethical clearance and permission for study. $\mathrm{HH}, \mathrm{TY}$, and HS: Supervised data collectors. $\mathrm{HH}, \mathrm{MH}, \mathrm{SKH}, \mathrm{PKH}, \mathrm{TY}, \mathrm{HS}$ and $\mathrm{SN}$ : Drafting the article or revisiting it critically for important intellectual content. TY, and HS: were project leaders and primary investigators of the study. All authors read and approved the final manuscript.

Funding support

None.

Availability of data and materials

The datasets used and/or analyzed during the current study are available from the corresponding author on reasonable request.

\section{Ethics approval and consent to participate}

The study design was approved by the regional Ethics Committee of Guilan University of Medical Sciences (IR.GUMS.REC.1398.444) and was in accordance with the declaration of Helsinki. However, the ethics committee waived the need for informed consent since only the medical records were used.

\section{Consent for publication}

Not applicable. All samples either swabs or aspiration were obtained from patients as parts of routine sampling during their hospitalization period, so the regional ethical committee waived the need for informed consent.

\section{Competing interests}

The authors declare that they have no competing interests. 


\section{Author details}

${ }^{1}$ Razi Clinical Research Development Unit, Razi Hospital, Guilan University of Medical Sciences, Rasht, Iran. ${ }^{2}$ Department of Microbiology, School of Medicine, Guilan University of Medical Sciences, Rasht, Iran.

Received: 24 June 2020 Accepted: 4 August 2020

Published online: 14 August 2020

\section{References}

1. Birhanu Y, Endalamaw A. Surgical site infection and pathogens in Ethiopia: a systematic review and meta-analysis. Patient Saf Surg. 2020;14(1):7. https://doi.org/10.1186/s13037-020-00232-y.

2. Amenu D, Belachew T, Araya F. Surgical site infection rate and risk factors among obstetric cases of Jimma university specialized hospital, southwest Ethiopia. Ethiop J Health Sci. 2011;21(2):91-100. https://doi. org/10.4314/ejhs.v21i2.69049.

3. Legesse Laloto T, Hiko Gemeda D, Abdella SH. Incidence and predictors of surgical site infection in Ethiopia: prospective cohort. BMC Infect Dis. 2017;17(1):119. https://doi.org/10.1186/s12879-016-2167-x.

4. Allegranzi B, Aiken AM, Zeynep Kubilay N, Nthumba P, Barasa J, Okumu $G$, et al. A multimodal infection control and patient safety intervention to reduce surgical site infections in Africa: a multicentre, before-after, cohort study. Lancet Infect Dis. 2018;18(5):507-15. https://doi.org/10.1016/s1473 -3099(18)30107-5.

5. Allegranzi B, Bagheri Nejad S, Combescure C, Graafmans W, Attar H, Donaldson L, et al. Burden of endemic health-care-associated infection in developing countries: systematic review and meta-analysis. Lancet. 2011;377(9761):228-41. https://doi.org/10.1016/s0140-6736(10)61458-4.

6. Gaynes RP, Culver DH, Horan TC, Edwards JR, Richards C, Tolson JS. Surgical site infection (SSI) rates in the United States, 1992-1998: the National Nosocomial Infections Surveillance System basic SSI risk index. Clin Infect Dis. 2001;33(Suppl 2):S69-77. https://doi.org/10.1086/321860.

7. Pathak A, Mahadik K, Swami MB, Roy PK, Sharma M, Mahadik VK, et al. Incidence and risk factors for surgical site infections in obstetric and gynecological surgeries from a teaching hospital in rural India. Antimicrob Resist Infect Control. 2017;6:66. https://doi.org/10.1186/s1375 6-017-0223-y.

8. Poggio JL. Perioperative strategies to prevent surgical-site infection. Clin Colon Rectal Surg. 2013;26(3):168-73. https://doi. org/10.1055/s-0033-1351133.

9. Mathur $P$, Singh S. Multidrug resistance in bacteria: a serious patient safety challenge for India. J Lab Phys. 2013;5(1):5-10. https://doi. org/10.4103/0974-2727.115898.

10. Eshaghi M, Bibalan MH, Pournajaf A, Gholami M, Talebi M. Detection of new virulence genes in mecA-positive Staphylococcus aureus isolated from clinical samples: the first report from Iran. Infect Dis Clin Pract. 2017;25(6):310-3. https://doi.org/10.1097/IPC.0000000000000506.

11. Sydnor ERM, Perl TM. Hospital epidemiology and infection control in acute-care settings. Clin Microbiol Rev. 2011;24(1):141-73. https://doi. org/10.1128/CMR.00027-10.

12. Patel SJ, Oliveira AP, Zhou JJ, Alba L, Furuya EY, Weisenberg SA, et al. Risk factors and outcomes of infections caused by extremely drugresistant gram-negative bacilli in patients hospitalized in intensive care units. Am J Infect Control. 2014;42(6):626-31. https://doi.org/10.1016/j. ajic.2014.01.027.

13. Siwakoti S, Subedi A, Sharma A, Baral R, Bhattarai NR, Khanal B. Incidence and outcomes of multidrug-resistant gram-negative bacteria infections in intensive care unit from Nepal-a prospective cohort study. Antimicrob Resist Infect Control. 2018;7:114. https://doi.org/10.1186/s1375 6-018-0404-3.

14. Horan TC, Gaynes RP, Martone WJ, Jarvis WR, Emori TG. CDC definitions of nosocomial surgical site infections, 1992: a modification of CDC definitions of surgical wound infections. Infect Control Hosp Epidemiol. 1992;13(10):606-8.

15. Tille PM. Bailey \& Scott's diagnostic microbiology. St. Louis, Missouri: Elsevier; 2014

16. CLSI. Performance Standards for Antimicrobial Susceptibility Testing. 30th ed. CLSI Supplement M100. Wayne, PA: Clinical and Laboratory Standards Institute; 2020.
17. Magiorakos AP, Srinivasan A, Carey RB, Carmeli Y, Falagas ME, Giske CG, et al. Multidrug-resistant, extensively drug-resistant and pandrug-resistant bacteria: an international expert proposal for interim standard definitions for acquired resistance. Clin Microbiol Infect. 2012;18(3):268-81. https://doi.org/10.1111/j.1469-0691.2011.03570.x.

18. Tartari E, Weterings V, Gastmeier P, Rodríguez Baño J, Widmer A, Kluytmans J, et al. Patient engagement with surgical site infection prevention: an expert panel perspective. Antimicrob Resist Infect Control. 2017;6:45. https://doi.org/10.1186/s13756-017-0202-3.

19. Alamrew K, Tadesse TA, Abiye AA, Shibeshi W. Surgical antimicrobial prophylaxis and incidence of surgical site infections at Ethiopian TertiaryCare Teaching Hospital. Infect Dis. 2019. https://doi.org/10.1177/11786 33719892267.

20. Krukerink M, Kievit J, Marang-van de Mheen PJ. Evaluation of routinely reported surgical site infections against microbiological culture results: a tool to identify patient groups where diagnosis and treatment may be improved. BMC Infect Dis. 2009;9:176. https://doi. org/10.1186/1471-2334-9-176.

21. Culver DH, Horan TC, Gaynes RP, Martone WJ, Jarvis WR, Emori TG, et al. Surgical wound infection rates by wound class, operative procedure, and patient risk index. National Nosocomial Infections Surveillance System. Am J Med. 1991;91(3b):152s-7s. https://doi.org/10.1016/00029343(91)90361-z.

22. Dessie W, Mulugeta G, Fentaw S, Mihret A, Hassen M, Abebe E. Pattern of bacterial pathogens and their susceptibility isolated from surgical site infections at selected Referral Hospitals, Addis Ababa. Ethiopia Int J Microbiol. 2016;2016:2418902. https://doi.org/10.1155/2016/2418902.

23. Alexiou K, Drikos I, Terzopoulou M, Sikalias N, loannidis A, Economou $\mathrm{N}$. A prospective randomised trial of isolated pathogens of surgical site infections (SSI). Ann Med Surg. 2017;21:25-9. https://doi.org/10.1016/j. amsu.2017.07.045.

24. Negi V, Pal S, Juyal D, Sharma MK, Sharma N. Bacteriological Profile of Surgical Site Infections and Their Antibiogram: A Study From Resource Constrained Rural Setting of Uttarakhand State. India. J Clin Diagn Res. 2015;9(10):Dc17-Dc20. https://doi.org/10.7860/jcdr/2015/15342.6698.

25. Mukagendaneza MJ, Munyaneza E, Muhawenayo E, Nyirasebura D, Abahuje E, Nyirigira J, et al. Incidence, root causes, and outcomes of surgical site infections in a tertiary care hospital in Rwanda: a prospective observational cohort study. Patient Saf Surg. 2019;13:10. https://doi. org/10.1186/s13037-019-0190-8.

26. Misteli H, Widmer AF, Rosenthal R, Oertli D, Marti WR, Weber WP. Spectrum of pathogens in surgical site infections at a Swiss University Hospital. Swiss Med Wkly. 2011;140:w13146. https://doi.org/10.4414/ smw.2011.13146.

27. Trinh JV, Chen LF, Sexton DJ, Anderson DJ. Risk factors for gram-negative bacterial surgical site infection: do allergies to antibiotics increase risk? Infect Control Hosp Epidemiol. 2009;30(5):440-6. https://doi. org/10.1086/596612.

28. Paterson DL. Serious infections in the intensive care unit: Pseudomonas aeruginosa and Acinetobacter baumannii. Clin Infect Dis. 2006;43(2):S41S4242. https://doi.org/10.1086/504473.

29. Wang M, Wei H, Zhao Y, Shang L, DI L, Lyu C, et al. Analysis of multidrugresistant bacteria in 3223 patients with hospital-acquired infections (HAl) from a tertiary general hospital in China. Bosn J Basic Med Sci. 2019;19(1):86-93. https://doi.org/10.17305/bjbms.2018.3826.

30. Nikaido H. Multidrug resistance in bacteria. Annu Rev Biochem. 2009;78:119-46. https://doi.org/10.1146/annurev.biochem.78.08290 7.145923.

31. Muntean D, Horhat F-G, Bădițoiu L, Dumitrașcu V, Bagiu I-C, Horhat D-I, et al. Multidrug-resistant Gram-negative Bacilli: a retrospective study of trends in a tertiary healthcare unit. Medicina. 2018;54(6):92. https://doi. org/10.3390/medicina54060092.

32. Jahangiri S, Malekzadegan Y, Motamedifar M, Hadi N. Virulence genes profile and biofilm formation ability of Acinetobacter baumannii strains isolated from inpatients of a tertiary care hospital in southwest of Iran. Gene Rep. 2019. https://doi.org/10.1016/j.genrep.2019.100481.

33. Hope D, Ampaire L, Oyet C, Muwanguzi E, Twizerimana H, Apecu RO. Antimicrobial resistance in pathogenic aerobic bacteria causing surgical site infections in Mbarara regional referral hospital, Southwestern Uganda. Sci Rep. 2019;9(1):17299. https://doi.org/10.1038/s41598-01953712-2. 
34. Martínez-Pastor JC, Vilchez F, Pitart C, Sierra JM, Soriano A. Antibiotic resistance in orthopaedic surgery: acute knee prosthetic joint infections due to extended-spectrum beta-lactamase (ESBL)-producing Enterobacteriaceae. Eur J Clin Microbiol Infect Dis. 2010;29(8):1039-41. https://doi. org/10.1007/s10096-010-0950-y.

\section{Publisher's Note}

Springer Nature remains neutral with regard to jurisdictional claims in published maps and institutional affiliations.
Ready to submit your research? Choose BMC and benefit from:

- fast, convenient online submission

- thorough peer review by experienced researchers in your field

- rapid publication on acceptance

- support for research data, including large and complex data types

- gold Open Access which fosters wider collaboration and increased citations

- maximum visibility for your research: over $100 \mathrm{M}$ website views per year

At BMC, research is always in progress.

Learn more biomedcentral.com/submissions 